\section{BIOPOLÍTICA, BIOTECNOLOGIAS E BIOMEDICINA}

\author{
Biopolitics, Biotechnology and Biomedicine \\ Biopolítica, Biotecnologías y Biomedicina \\ Biopolitique, Biotechnologie et Biomédecine
}

\author{
Biopolítica e Subjetividades \\ Contemporâneas
}

\section{Resumo}

O artigo constitui um ensaio livre, no qual se busca abordar alguns aspectos ou faces das relações entre biopolítica, biotecnologias e biomedicina, perspectivando-os em referência a um quadro de fundo mais amplo, a saber: o de um niilismo eminentemente biopolítico, característico do novo capitalismo que tomou vulto aproximadamente desde a segunda metade da década de 1970, e que é neoliberal, globalizado, transnacional, financeiro e conexionista. $\mathrm{O}$ artigo está dividido em duas partes. Na primeira, são examinados, sem pretensões exaustivas, por um lado, alguns fatores considerados relevantes ao estabelecimento de novos agenciamentos entre biopolítica e biotecnologias, e, por outro, continuidades e rupturas a serem observadas no exercício da biopolítica, na transição entre as sociedades modernas, regidas por uma lógica disciplinar, e as sociedades contemporâneas, regidas por uma lógica do controle. Os estudos e pesquisas de Nikolas Rose são, para tanto, privilegiados como intercessores importantes para as considerações feitas. Na segunda parte, por sua vez, o artigo busca descrever, caracterizar, diferenciar e comentar, mesmo que de forma sucinta, três distintas versões de "projetos imortalistas", isto é, de projetos que envolvem uma articulação entre biopolítica, biotecnologias e biomedicina, constituídos no período que se estende do início do século XX até o nosso presente, com o intuito de driblar, contornar, evitar, ou superar a morte, isto é, a finitude humana.

Palavras-chave: biopolítica; biotecnologias; biomedicina; imortalismo; singularidade.

\section{Abstract}

The article is a free trial in which it seeks to address some aspects or faces of the relationship between biopolitics, biotechnology and biomedicine, viewing them in reference to a wider background picture, namely of a highly bio-political nihilism, characteristic of the new capitalism that has taken shape since about the second half of the 1970s, which is neoliberal, globalized, transnational, financial and connectionist. The article is divided into two parts. In the first one, without extensive claims, on one hand, some factors considered relevant to the establishment of new assemblages between biopolitics and biotechnologies are examined, and on the other, continuities and ruptures to be observed in the exercise of biopolitics, the transition between modern societies governed by a disciplinary logic, and contemporary societies, governed by a control logic. Nikolas Rose's studies and researches are, therefore, privileged as important intercessors for the considerations made. In the second part, the article seeks to describe, characterize, distinguish and comment, even briefly, three different versions of "immoralist's projects", i.e. projects involving a link between biopolitics, biotechnology and biomedicine, in a period extending from the early twentieth century to our present, in order to bypass, contour, avoid or overcome death, that is, human finitude.

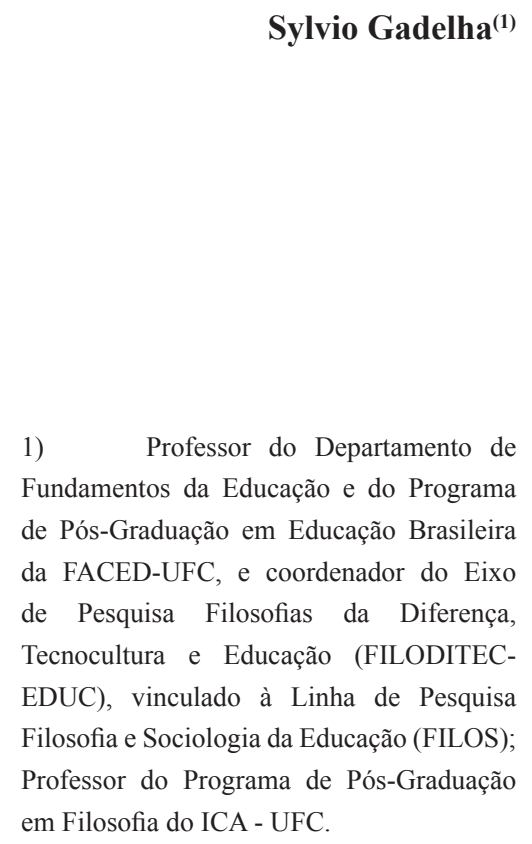

em Filosofia do ICA - UFC. 


\section{Resumen}

Este artículo es un ensayo libre al cual se busca abordar algunos aspectos de las relaciones entre biopolitica, biotecnología y biomedicina, haciendo una perspectiva en referencia a un cuadro de fondo más amplio, eso es: lo de un nihilismo eminentemente biopolítico, característico del nuevo capitalismo que tomó cara aproximadamente desde la segunda mitad de la década de 1970, que es neoliberal, globalizado, transnacional, financiero y conectistas. El artículo está dividido en dos partes. En la primera son examinados, sin pretensiones agotadoras, por un lado, algunos puntos considerados relevantes al establecimiento de nuevos negocios entre biopolitica y biotecnologías, y, por otro, continuidades y roturas que serán observadas en el ejercicio de la biopolítica, en la transición entre las sociedades modernas, regidas por una lógica disciplinar, y las sociedades contemporáneas, regidas por una lógica del control. Los estudios e investigaciones de Nikolas Rose son privilegiados como intercesores importantes para las consideraciones hechas. En la segunda parte, por su vez, el artículo busca describir, caracterizar, diferenciar y comentar, aunque de forma resumida, tres diferentes versiones de "proyectos imortalistas", es decir, proyectos que envuelven una articulación entre biopolitica, biotecnologías y biomedicina, constituidos en el periodo que va del inicio del siglo XX hasta nuestro presente, con el objetivo de driblar, contornear, evitar o superar la muerte, es decir, la finitud humana.

Palabras clave: biopolitica; biotecnologías; biomedicina; inmortalidad; singularidad.

\section{Résumé}

L'article constitue un libre essay dont le but est analyser quelques aspects des relations entre biopolitique, biotechnologie et biomédecine à partir d'une perspective d'un contexte plus large : un nihilisme éminemment biopolitique caractéristique du nouveau capitalisme qui a apparu dès la deuxième moitié de la décade de 1970, le néolibéral, globalisée, transnational, financier et connexioniste. L'article a deux parties. À la première partie, d'un côté, quelques facteurs considérés importants à la nouvelle articulation entre biopolitique et biotechnologie sont examinés sans des prétentions épuisantes et, d'autre côté, examiner aussi les continuités et ruptures vues à l'exercice de la biopolitique à la transition entre les sociétés modernes, dirigées par la logique de la discipline, et les sociétés contemporaines régies par la logique du contrôle. Les études et les recherches de Nikolas Rose sont la base théorique privilégié des considérations faites. À la deuxième partie, l'article a le but de décrire, caractériser, différencer et commenter, d'une manière concise, trois différentes versions des "projets immortalistes ", c'est-à-dire, des projets qui présentent l'articulation entre biopolitique, biotechnologie et biomédecine, constitués à la période du début du XXe siècle jusq'aujourd'hui avec l'intention de dépasser, contorner, éviter ou surpassar la mort, la finitude humaine.
Mots-clés: biopolitique; biotechnologies; biomédecine; imortalité.

$$
\begin{array}{r}
\text { Planejar sua imortalidade significa passar a vida } \\
\text { pensando na morte... (Gray, 2014) }
\end{array}
$$

O filósofo Pelbart (2013) nos sugere que, em nossa contemporaneidade, a última expressão daquilo que Nietzsche designou de niilismo é justamente a biopolítica. Esta atestaria que o primeiro, mesmo travestido, continua vivo e atuante entre nós. O niilismo contemporâneo teria, por assim dizer, um caráter eminentemente biopolítico. Tudo se passa como se nossa atualidade padecesse de uma espécie de mal-estar, para não falar de uma enfermidade, que desvitalizaria parte considerável do tecido social, particularmente daqueles segmentos sociais formados por indivíduos, grupos e coletividades pobres, marginalizados, excluídos, ou em vias de sê-lo. Engana-se, todavia, quem pensa que seus efeitos se limitariam apenas a esses estratos populacionais desfavorecidos, pois também se fariam sentir junto aos ditos incluídos, em maior ou menor grau, e de diferentes formas. Em que sentido, no entanto, Pelbart concebe esse tipo de niilismo que nos ronda e nos atinge?

Segundo Pelbart (2013, p. 13), seu principal sintoma remete a um estado de coisas no qual convivem com crescente pusilanimidade "um alargamento indefinido dos modos de rebaixamento e monitoramento biopolítico da vida e uma imensa dificuldade em extrair desse contexto a variabilidade das perspectivas dos modos de existência e de resistência que ele poderia suscitar". Esse ensaio partilha desse diagnóstico e pretende trabalhar algumas questões e dilemas a ele implicados, dividindo-se basicamente em duas partes. $\mathrm{Na}$ primeira delas, intitulada "Biopolítica e biotecnologias: novos agenciamentos, continuidades e rupturas", busca articular a biopolítica às novas biotecnologias, apontando algumas mudanças mais gerais em racionalidades e tecnologias de governo, tal como elas se apresentam no contexto das sociedades liberais mais desenvolvidas. A segunda parte, intitulada "Biopolítica, biomedicina, imortalidade e singularidade, ocupa-se em explorar, mesmo que de forma concisa e descritiva, um dos efeitos, ou sintomas da conjugação entre biopolítica, biotecnologias e governamentalidade neoliberal, (ou pósneoliberal), nesse novo milênio, qual seja: o projeto de se retardar o envelhecimento humano e, no limite, driblar a morte e conquistar a imortalidade através dos avanços na biomedicina. Como esse projeto, todavia, tem alguns antecedentes, mesmo que envolvendo circunstâncias histórico-sociais distintas, retrocede-se ao início do século XX para melhor situá-lo e para melhor acompanhar seus desdobramentos, até os primeiros anos desse novo milênio. 


\section{Biopolítica e Biotecnologias: Novos Agenciamentos, Continuidades e Rupturas}

Qualquer esforço que tenha por intuito empreender uma ontologia histórica de nós mesmos, tal como sugerida por Michel Foucault, não pode deixar de levar em conta alguns fatores, dentre os quais poderiam se destacar, além dos que foram brevemente apontados há pouco, as revoluções operadas nos campos das tecnologias da informação, da comunicação (TICs) e das biotecnologias. Nesse sentido, um dos principais desafios que se colocam ao pesquisador arqueogenealogista, ou anarqueologista é identificar, descrever, compreender e estimar quais as diversas implicações das TICs e das novas biotecnologias à biopolítica contemporânea, à arte de governar neoliberal e, mais amplamente, ao que Deleuze (1992) denominou de sociedades de controle, isso, contudo, sem perder de vista que estas também se caracterizam pelo fato de serem sociedades em que se pode localizar uma forma de vida emergente, para falar com Rose (2013), e sociedades em que ganham corpo e vulto tanto um dispositivo de segurança quanto um dispositivo do empreendedorismo, o qual remete a um empresariamento generalizado da vida, isto é, à sua mercadização, mercantilização, ou, ainda, como sugere Rifkin (2001), à "comoditização" das relações humanas.

Detenhamo-nos, muito rapidamente, nessa nova forma de vida que, segundo Rose (2013), estaria emergindo desde mais ou menos a passagem do século XX para o século XXI até os nossos dias: Em primeiro lugar, ela se expressaria, sobretudo, por toda uma ambiência biotecnológica, na qual se observaria uma convergência de inúmeras e distintas novas tecnologias (informática, genômica, farmacogenômica, robótica, inteligência artificial (AI), biônica, bioengenharia, neurociências, nanotecnologia, biomedicina etc.). Em segundo lugar, essa vida emergente seria movida por uma nova bioeconomia, na qual se destacam, dentre outros, tanto a presença central quanto a ação dos grandes laboratórios de fármacos e psicofármacos, conforme destaca Carneiro $(2011, \mathrm{~s} / \mathrm{p})$ :

A indústria farmacêutica, no seu conjunto, concentra alguns dos maiores grupos empresariais do planeta. Hiperconcentrada, hiperlucrativa e em acelerado crescimento nas últimas décadas (faturou 773 bilhões de dólares em 2008). Estreitamente vinculada ao setor de produção de sementes transgênicas e agrotóxicos, esta indústria fundiu-se com a de alimentos por meio de várias compras e fusões empresariais. O ramo do tabaco também está imbricado com o setor alimentar e farmacêutico. A última ameaça global pandêmica da gripe suína representou um crescimento ainda mais explosivo da indústria farmacêutica que já era um dos mais expansivos e poderosos.
Como salienta Carneiro (2011), a ação desses grandes laboratórios se revela das mais relevantes, tendo em vista que, de um lado, eles operam ao nível microfísico, estendendo-se ao governamento de condutas e à produção de subjetividade, interferindo significativamente, portanto, nos modos mediante os quais os indivíduos passam a cuidar de si mesmos e a constituírem para si bioidentidades:

Muito além do simples e indefinível efeito farmacológico objetivo, todo remédio também é uma representação que se auto-reforça por meio do efeito-placeboinerente a todo medicamento. $\mathrm{O}$ que se vende com o mercado de drogas são modos de produção da subjetividade. Assim o fazem os usuários que as inserem em contextos sociais, cerimoniais e até rituais. Também assim o consideram as agências publicitárias que, ao promoverem álcool, tabaco ou remédios, vendem estados de espírito, modelos de felicidade da alma, humor em pílulas. Mais do que venderem, exacerbam, pois, conforme a hipnótica cantilena publicitária, só há requinte com um cigarro na mão, só há festa com cerveja e decotes generosos, só há felicidade plena com o sono, a ansiedade e a tristeza geridos por meio de doses de pílulas ou elixires. (Carneiro, 2011, s/p)

Por outro lado, esses grandes laboratórios também atuam no âmbito macrossocial, apresentando-se como agentes privilegiados no cenário biopolítico contemporâneo. Sua atuação se dá, ademais, ainda segundo Carneiro (2011), em estreita sintonia com processos que reproduzem as desigualdades e processos de exclusão sociais:

A África tem apenas $1 \%$ do mercado farmacêutico, embora tenha epidemias como a da Aids que necessitariam enormemente de medicamentos. Desde o início do século 21, a África do Sul ameaçou desafiar o regime de patentes que impedia a venda barata de produtos monopolizados por grandes laboratórios e [ameaçou] começar a produzir genéricos num laboratório indiano. A patente do retroviralstavudinepertence à universidade de Yale (e rende 90\% dosroyaltiesdessa universidade, várias centenas de milhões de dólares), mas ela a cedeu em exclusividade para o laboratório Squibb (BMS), que após uma grande disputa ofereceu o medicamento a um preço menor para os africanos, mas sem quebrar o seu monopólio.

Esse monopólio de patentes como direito de propriedade intelectual representa uma forma de exclusivismo na circulação do conhecimento e é um dos pilares da forma atual de funcionamento do comércio internacional que favorece a acumulação de capital em detrimento dos interesses sociais da maioria da humanidade. (Carneiro, $2011, \mathrm{~s} / \mathrm{p})$ 
No estrato histórico-societal em que viceja essa ambiência biotecnológica, Lima (2010) identifica a emergência de um novo paradigma científico, isto é, de um modelo referencial a que ele designa por "pós-humanismo cibernético-informacional de matriz molecular-digital". A esse paradigma se associam noções como as de "cibernética", "neurociências", "transhumanismo", "singularidade", "imortalidade" e "pós-humano", para ficar só em algumas delas, mas também questões e/ou dilemas relacionados à "inovação", à bioética, à neuroética, à sustentabilidade e à incômoda e assustadora possibilidade de um retorno de práticas e políticas eugênicas, todos envolvendo, em maior ou menor medida, possíveis violações do que seria natureza humana e o desrespeito à dignidade humana. De outra parte, inscrevem-se nesse paradigma, por exemplo: 1) a ideia de se conceber a vida humana como infinitamente maleável e passível de molecularização; a manipulação genética; 2) o agenciamento de genomas às novas tecnologias reprodutivas; 3 ) o prolongamento cada vez maior da vida e, no limite, a possibilidade de em breve se exorcizar definitivamente a morte; 4) a fusão entre o artificial e o orgânico, entre o silício e o carbono, ou, em outros termos, o desmanchamento das fronteiras que até então distinguiam os primeiros dos segundos; 5) a invenção de novas técnicas biomédicas (xenotransplantes, engenharia de tecidos, cultivo de células-tronco; dentre outros).

Retomando, agora, aquela complicada e desafiadora empresa de se proceder a uma ontologia do presente, nela atribuindo especial atenção, como disse antes, às relações transversais e imanentes entre as diversas novas tecnologias, tais como se encontram mutuamente implicadas à biopolítica e à governamentalidade que agem em meio às sociedades de controle, talvez seja necessário considerar que, em decorrência das múltiplas e recíprocas relações de implicação entre todos os fatores elencados nos parágrafos anteriores, o próprio conceito de biopolítica tenha de ser redefinido e alargado, apontando, doravante, para uma nova forma de "política vital", isto é, para o que Rose (2013) chama de "política da própria vida". Mesmo admitindo que haja continuidades entre a biopolítica praticada nos séculos XVIII-XIX e aquela que se tem praticado do final do século $\mathrm{XX}$ até o presente momento, não há como desconsiderar, contudo, algumas mudanças e descontinuidades que terminaram por reconfigurar o jogo de forças biopolítico no cenário do novo milênio. A esse respeito, permitam-nos citar um longo, mas oportuno e esclarecedor trecho de $A$ política da própria vida, de Rose (2013, pp. 14-15):

Correndo o risco de simplificação, poder-se-ia dizer que a política de vida dos séculos XVIII e XIX era uma política da saúde - das taxas de nascimento e de morte, de doenças e epidemias, do policiamento da água, de saneamento, gêneros alimentícios, cemitérios e da vitalidade daqueles aglomerados em cidades e metrópoles. Ao longo da primeira metade do século $\mathrm{XX}$, essa preocupação com a saúde da população e sua qualidade foi impregnada por uma compreensão particular da herança de uma constituição biológica e das consequências da reprodução discriminatória de diferentes subpopulações; isso pareceu obrigar os políticos de muitos países a tentar administrar a qualidade da população, muitas vezes coercitivamente $\mathrm{e}$, às vezes, mortiferamente, em nome do futuro da raça. No entanto, a política de vida de nosso século parece bem diferente. Não está delimitada nem pelos polos de doença e saúde, nem focalizada em eliminar patologias para proteger o destino da nação. Ao contrário, está preocupada com nossas crescentes capacidades de controlar, administrar, projetar, remodelar e modular as próprias capacidades vitais dos seres humanos enquanto criaturas viventes. É, como procuro demonstrar, uma "política da vida em si mesma".

Enquanto muitos dos temas dessa política contemporânea da vida são familiares, outros são novos. Algo dessa novidade reside em mudanças mais gerais em racionalidades e tecnologias de governo, principalmente nas transformações no fornecimento de segurança, bemestar e saúde associados aos desafios ao Estado social na Europa e na Australásia, e no surgimento de novas tecnologias governamentais "liberais avançadas". [...]. De modo geral, estes envolveram uma reorganização dos poderes do Estado, com a devolução de muitas responsabilidades para a administração da saúde e da reprodução humanas, que, no decurso do século $\mathrm{XX}$, tinham sido responsabilidade do aparato formal de governo: devolvê-las a entidades regulatórias quase autônomas - comissões de bioética, por exemplo; a corporações privadas - como clínicas privadas de fertilidade e companhias de biotecnologia que vendem produtos tais como testes genéticos, diretamente aos consumidores; e a grupos profissionais - tais como associações médicas - regulados "a distância" por mecanismos poderosos de auditorias, padrões, pontos de referência e orçamentos.

Nesse misto de cenário e campo de forças, entrechocamse, de um lado, interesses do mundo corporativo, principalmente dos conglomerados empresariais que integram laboratórios farmacêuticos, indústria dos agronegócios e de produtos estéticos, com seus poderosos lobbies. De outro lado, interesses político-econômicos do Estado e das agências estatais. E de outro lado, ainda, interesses que tanto podem ser os de agremiações e/ou partidos políticos, quanto os de movimentos minoritários da sociedade civil, além dos de entidades classistas de profissionais liberais, com seus respectivos comitês de ética, acompanhamento e avaliação, suas comissões de vigilância e seus grupos de pressão, todos engajados, em maior ou menor medida, de 
uma forma de outra, no intuito de ter a maior influência e poder de decisão possíveis no esboço, na definição e no efetivo estabelecimento de uma linha que sirva de referência para o que deve ser permitido, para o que deve ser regulado, e, por fim, para o que deve ser proibido.

Talvez este seja um momento oportuno para, de passagem, remetermo-nos a uma formulação feita por Arantes (2014, p. 1), a propósito da dificuldade, em nosso presente, de discernimos a diferença entre "a ebulição participativa dos movimentos sociais e o protagonismo da sociedade civil exigido pelo grande capital privatizante quer dizer, entre a nova esquerda e a nova direita". Ora, creio que isso importa a todos os que se interessam e se ocupam da biopolítica e da governamentalidade neoliberal. No final do século XX, a gestão tipicamente liberal do par liberdade-segurança, a fim de melhor conduzir, controlar e modular as condutas dos indivíduos e coletividades, essa nova arte de governar recorre estrategicamente a três coisas: em primeiro lugar, ao princípio de equidade (segundo o qual, para o que aqui importa, cada caso é um caso); em segundo e em terceiro lugar, respectivamente, a uma flexibilização e de uma terceirização generalizadas, através das quais os próprios indivíduos, as comunidades, os movimentos, as organizações, as escolas e outros coletivos, em nome da democratização, de maior liberdade, de maior autonomia, do protagonismo, do empoderamento, do exercício qualificado da cidadania, da criatividade, da eficácia, da eficiência e, inclusive, de um "direito à diferença", são convocados, induzidos e estimulados a participarem ativamente da vida social, encarregando-se e responsabilizando-se eles próprios, na qualidade de parceiros do Estado, ou das empresas, e como gestores de si mesmos, da melhoria de suas condições de vida e do desenvolvimento sustentável das sociedades em que vivem.

Se acrescentarmos, a esse dado, outro, sagazmente captado por Foucault (2008), isto é, o de que essa arte de governar também constitui uma espécie de tema-programa, no qual e desde o qual se dá uma otimização dos sistemas de diferença, garantindo assim tanto um espaço livre para processos oscilatórios, quanto tolerância aos indivíduos e às práticas minoritárias, vemos que ela perfaz, do mesmo modo, uma sofisticada espécie de programação ambiental, de perfil neobehaviorista, só que, agora, estabelecendo o condicionamento/governo das condutas apenas indiretamente, através de ações que incidem mais propriamente sobre as regras do jogo, isto é, sobre o ambiente, determinando as relações de sociabilidade, de mando e de obediência, de cuidado de si e de cuidado do outro. Esse é, com efeito, um dado crucial ao entendimento não só das novas formas de exercício de poder, de controle e das novas tecnologias de governo das condutas, mas também ao entendimento de como os governados podem vir a encarnar resistências aos mesmos.

De todo modo, vemos nitidamente como essa tendência ao empoderamento e ao protagonismo se fazem presentes no novo cenário biopolítico, marcado por aquela ambiência biotecnológica de que falava há pouco. Para Rose (2013, pp. 16-17), ela comparece associada tanto à auto-responsabilização pela saúde e pela segurança, quanto a um deslocamento em relação àquilo de que, doravante, devemos nos ocupar cada vez mais em nós mesmos, bem como ao modo e à escala com que o fazemos:

Essas modificações nas racionalidades e nas tecnologias de governo também implicaram crescente ênfase sobre a responsabilidade dos indivíduos na administração dos próprios negócios, na provisão da própria segurança com um prudente olho no futuro. Em nenhuma parte elas foram mais eloquentes do que no campo da saúde, onde os pacientes são cada vez mais estimulados a tornarem-se consumidores ativos e responsáveis de serviços médicos e de produtos que vão de drogas medicinais a tecnologias de reprodução e testes genéticos [...]. Essa complexa mercadização, autonomização e responsabilização conferem um caráter particular à política contemporânea da vida em democracias liberais avançadas.

Além e acima dessas mudanças, talvez, a novidade da biopolítica contemporânea surge da percepção que experimentamos uma "mudança de cadência", um crescimento qualitativo em nossas capacidades de manipular nossa vitalidade, nosso desenvolvimento, nosso metabolismo, nossos órgãos e nossos cérebros. Essa mudança de cadência envolve uma alteração em escala. $\mathrm{O}$ conhecimento biomédico e as técnicas que se estão desenvolvendo atualmente têm muitas diferenças, mas deveras têm algo em comum. Atualmente, no nível molecular é que a vida humana é compreendida, no nível molecular é que seus processos podem ser anatomizados, e no nível molecular é que a vida agora pode ser manipulada. Nesse nível, parece, nada existe de místico ou de incompreensível acerca de nossa vitalidade - quaisquer coisas e todas as coisas parecem, em princípio, ser inteligíveis e, consequentemente, abertas a intervenções calculadas a serviço de nossos desejos acerca dos tipos de pessoas que nós mesmos e nossos filhos queremos ser. Portanto, até mesmo as contestações que estão surgindo em torno de cada uma dessas questões, desde as células-tronco às drogas leves, são modeladas parcialmente, pelas oportunidades e ameaças que tal visão molecular da vida parece ensejar. Visto que os seres humanos chegam a experimentar a si mesmos de novas maneiras como criaturas biológicas, como si-mesmos biológicos, sua existência vital torna-se foco de governo, alvo de novas formas de autoridade e de expertise, um campo altamente catéxico para o conhecimento, um território em expansão para a exploração bioeconômica, um princípio organizador de ética e uma aposta em uma 
política de vida molecular.

\section{Biopolítica, Biomedicina, Imortalidade e Singularidade}

Leonid Krasin (1870-1926) foi um personagem curioso. Além de engenheiro, ex-terrorista anticzarista, especialista em explosivos, contrabandista de armas, falsário, operador de lavagem de dinheiro, principal financista bolchevique, após a revolução russa tornou-se Comissário do Povo Soviético para o Comércio Exterior. Coube justamente a ele a responsabilidade de constituir uma equipe funerária que teria a honrosa tarefa de congelar o corpo recémembalsamado de Lênin, na esperança de que um dia, ainda que num futuro incerto, este pudesse vir a ser ressuscitado, desde que finalmente se contasse com tecnologias que o permitissem. A equipe foi formada, batizada com o extravagante nome de "Comissão de Imortalização" e, de fato, efetuou o referido procedimento criogênico, dispondo, inclusive, para tanto, de um refrigerador alemão, exemplo da tecnologia de ponta da época. No fim das contas, porém, essa audaciosa e desmedida empresa não foi bem sucedida, frustrando assim as expectativas não só de Krasin, mas também de Anatóli Lunatchárski (1875 - 1933), do artista suprematista Kazimir Malevitch (1879-1935), do arquiteto construtivista A. V. Shchusev (1873-1949) e do líder supremo Stalin, todos entusiastas do projeto criogênico e engajados na construção do mausoléu de Lênin (Gray, 2014).

Esse pitoresco caso serve de pretexto para assinalar a existência, na Rússia daquela época, de um curioso credo, o qual, estranhamente, conjugando elementos de natureza científica e elementos místicos e religiosos, angariou simpatias e adeptos fervorosos os mais diversos, desde místicos até renomados cientistas, intelectuais, escritores, jornalistas e artistas. O episódio do congelamento do corpo de Lênin dá a ver a crença de que a ciência poderia proporcionar a imortalidade física, crença esta perfeitamente sintonizada à fé ortodoxa russa na ressurreição física. Leonid Krasin, Lunatchárski e o eminente neurologista Vladimir Bechterev (1857-1927), por exemplo, vinculavam-se a um movimento conhecido como “AConstrução de Deus", o qual, perfazendo um culto de mistérios, porém de índole secular, pregava que o ocultismo e a ciência poderiam muito bem caminhar de mãos dadas. Como afirma Gray (2014, p. 132), em seu fascinante livro A busca pela imortalidade: a obsessão humana em ludibriar a morte, os "construtores de Deus" acreditavam que "um verdadeiro revolucionário deveria ter como propósito deificar a humanidade, empreitada que envolvia a abolição da morte". ${ }^{1}$ Vale a pena seguir as

1 Ainda segundo Gray (2014), dentre os personagens relacionados palavras com as quais escritor Máximo Gorki (citado em Gray, 2014, p. 133) expressa essa tão esperada deificação, associando-a a uma aniquilação da matéria, fenômeno que deveria teria lugar em algum momento incerto do futuro:

Pessoalmente, prefiro imaginar o Homem como uma máquina que transmuta, dentro de si, a assim chamada "matéria morta" em energia e vontade psíquicas, em algum futuro longínquo, e transforma o mundo inteiro em um mundo inteiramente psíquico. [...] Nesse tempo, nada existirá exceto o pensamento. Tudo desaparecerá, sendo transmutado em pensamento puro, que só ele existirá, encarnando todo o espírito da humanidade. Em alguma época futura, toda a matéria absorvida pelo Homem será transmutada por ele e por seu cérebro em uma única energia - uma energia psíquica. Essa energia descobrirá a harmonia que existe nela mesma e mergulhará na autocontemplação - uma meditação sobre todas as infinitas possibilidades de criação nela encerradas.

Sigamos adiante e observemos que o projeto criogênico, com o passar das décadas, perdeu força, só retornando à baila na década de 1960, particularmente com o advento de dois livros que buscavam reativá-lo, a saber, The prospect of immortality (A perspectiva de imortalidade), de Robert Ettinger, e The imortalist: an approach to the engineering of man's divinity ( $\mathrm{O}$ imortalista: uma abordagem da engenharia da divindade do homem), de Allan Harrington, publicados, respectivamente, em 1964 e 1969. Comparando aquele primeiro projeto criogênico com esses dois últimos, três observações talvez sejam pertinentes: a primeira, é que embora já não houvesse mais lugar para que se acalentasse a esperança quanto à existência de vida após a morte, nem por isso se abandonou nos últimos a ambição de se derrotar esta última, para o que se continuou contando com o importante auxílio da ciência; a segunda observação, por sua vez, alude à ideia de que, após um congelamento bem sucedido, e o consequente ressuscitamento, abria-se a possibilidade de um remodelamento da vida humana, a qual compreendia tanto a correção e/ou cura de suas imperfeições-doenças, quanto a maximização e o aperfeiçoamento de suas habilidades e destrezas. É nesse sentido que devemos tomar as palavras de Ettinger (citado por Gray, 2014, p. 190):

A diferença-chave estará nas pessoas: nós remodelaremos, mais perto do desejo do coração, não apenas o mundo, mas a nós mesmos [...]. Você e eu, os congelados, os

em maior ou menor medida ao movimento, e dentre seus adeptos e/ou simpatizantes, além dos já citados, encontramos nomes como H. G. Wells (1866-1946), Máximo Gorki (1868-1936), Ernst Mach (1838-1936), Ernst Haeckel (1834-1919), Rudolf Steiner (1861-1925), Madame Blavátski (1831-1891), G. I. Gurdjieff (1866-1949), Trofim Lysenko (1898-1976), Konstantin Tsiolkovski (1837-1935) e Piotr Uspenski (1878-1947). 
ressuscitados, seremos não apenas revividos e curados, mas aumentados e melhorados, tornados aptos para trabalhar, brincar e talvez lutar, em grande escala e em grande estilo.

A terceira observação, por fim, diz respeito ao fato de que aquela ideia de deificação da humanidade passar a assumir um caráter cada vez mais emergencial, lutando contra o tempo e num permanente embate contra os processos responsáveis pela degeneração humana; tal é o que se depreende da seguinte passagem de Harrington (citado por Gray, 2014, pp. 190-191):

Nossa sobrevivência, sem o Deus que uma vez conhecemos, reduz-se agora a uma corrida contra o tempo [...]. A salvação por quaisquer meios e com rapidez. Tornou-se a paixão central que nos motiva, necessidade que rapidamente se torna demanda imperiosa, a ser resgatada do nada [...]. Chegou o tempo de os homens se transformarem em deuses ou perecerem [...]. Somente dominando os processos que nos forçam a ficar velhos seremos capazes de nos isentar da morte, do grupo dos animais, e assumir a condição de deuses, nossa legítima herança.

Mas, então, como se buscou combater com celeridade os efeitos da degeneração física? A partir da década de 1970, tem-se uma série, no campo da informática, que se estende da invenção do computador pessoal (PC), à arpanet e à internet, passando por um crescimento exponencial da capacidade de armazenamento de dados e de processamento de informações (evolução que corresponde à miniaturização de circuitos integrados de transístores). Por outro lado, também a partir daquela mesma década, tem-se outra série, agora no campo da biologia, que corre, pelo menos de início, mais ou menos em paralelo à primeira, que tem início com a possibilidade, aberta por Paul Berg, de se ligar distintas cadeias de DNA; que prossegue com o domínio das operações referentes às enzimas de restrição, fruto dos esforços de cientistas como Werner Arber, Daniel Nathans e de Hamilton O. Smith; e que dá um passo adiante com a primeira tentativa bem sucedida de sequenciamento de um gene humano, realizada por Francis Collins e Lap-Chee Tsui.

Aos poucos, com o desenvolvimento de ambas as séries, vão se dando as condições de possibilidade para que houvesse uma significativa convergência tecnológica entre informática e biologia, além de outras sinergias envolvendo campos científicos correlatos, dando ensejo, portanto, a uma verdadeira revolução biotecnológica, culminando, dentre outras coisas, com o projeto genoma, com o desenvolvimento da engenharia genética e dos transgênicos, com o desenvolvimento da nanotecnologia e das neurociências, com a emergência e a integração de novas especializações biomédicas e, por fim, em decorrência, com aplicações de todas essas novas tecnologias à sociedade, particularmente nos campos da saúde, da estética e dos agronegócios. É justamente em meio a essa ambiência e em meio a uma bioeconomia extremamente dinâmica e pungente, que irá emergir um terceiro projeto biotecnológico almejando a conquista da imortalidade.

A Revista ISTO É, de 24 de fevereiro de 2012, na seção "Medicina \& Bem-Estar", faz uma reportagem especial com o título "A era dos homens imortais", cuja chamada vem nas seguintes palavras: "Recursos como próteses para substituir neurônios, máquinas que constroem DNA, coração e até outro cérebro permitirão que a próxima geração viva pelo menos até os 150 anos - e as sucessoras, ainda muito mais". O texto da reportagem, por sua vez, de autoria de Oliveira (2012), começa dizendo o seguinte:

O ano será 2045. Ele marcará o início de uma era em que a medicina poderá oferecer à humanidade a possibilidade de viver por um tempo jamais visto na história. Órgãos que não estejam funcionando poderão ser trocados por outros, melhores, criados especialmente para nós. Partes do coração, do pulmão e até o cérebro poderão ser substituídos. Minúsculos circuitos de computador serão implantados no corpo para controlar reações químicas que ocorrem no interior das células. Estaremos a poucos passos da imortalidade. (p. 1)

O tom do texto, oscilando entre o fascínio, a incredulidade, o regozijo e o triunfalismo, muito provavelmente é o mesmo encontrado em uma infinidade de matérias semelhantes, que exploram o assunto de forma espetacularizada nos meios de comunicação de massa, sejam eles impressos, ou digitais. Ao mesmo tempo, ele também é testemunho da entrada em cena de uma nova discursividade sobre o que constitui a nossa verdade, sobre como podemos e devemos nos ocupar de nós mesmos, sobretudo, de nosso corpo, além de dar a ver a ação de novas tecnologias de si, isto é, de governamento do "Eu" e da própria conduta, tecnologias estas que se definem no entrecruzamento e articulação de valores, princípios, saberes e práticas oriundos, em primeiro lugar, do mundo corporativo; em segundo, do mundo esportivo, e; em terceiro, do mundo científico, em particular, da biomedicina.

Atravessando todos esses campos, no entanto, podese identificar sem dificuldade a inserção estratégica do imperativo da maximização da performance, não só pessoal, mas também familiar, grupal e/ou organizacional, maximização está elevada praticamente à categoria de culto. Nessa nova matriz de governo e governamento das condutas, o cuidado de si já não obedece tão somente às injunções disciplinares e normalizadoras de caráter médico-psi, tal como se apresentavam na segunda metade do século XIX e em boa parte do século XX. Com efeito, 
desde o final do século passado o cuidado de si tendeu a ser também orientado de acordo com as prescrições do campo do management e da autoajuda, de modo que as assim chamadas questões existenciais foram gradativa e sutilmente convertidas em questões empresariais, ou seja, em questões a serem enfrentadas com saberes e técnicas concernentes à administração e à gestão empresarial.

Por outro lado, a referida reportagem também se encarrega de apresentar ao grande público os espíritos empreendedores, os inovadores e também portadores das boas notícias e das novas possibilidades abertas, tanto para agora, quanto para breve, aos interessados em retardar ao máximo o seu envelhecimento, ou mesmo aos que sonham em escapar ao que até bem pouco tempo se considerava uma inexorável fatalidade, a morte. Meio "magos", meio cientistas, eles são, por exemplo, George Church professor de Harvard; Aubrey de Grey, gerontologista e biomédico especializado em antienvelhecimento; e Raymond ("Ray") Kurzweil,cientista, engenheiro,inventor,escritor,empresário e futurólogo, além de professor do Massachusetts Institute of Technology (Instituto de Tecnologia de Massachussets MIT), e cofundador, juntamente com Peter Diamandis, da futurista e elitista Universidade da Singularidade, encravada no Vale do Silício. Esta, segundo Cadwalladr (2012, s/p), é uma instituição "altamente conectada em rede, alimentada por um coquetel de filantrocapitalismo e dotada de uma consciência quase mística de seu próprio destino". Mas voltando aos protagonistas dessa odisseia, limitar-me-ei a fazer algumas considerações sobre Kurzweil, na medida em que talvez ele seja a figura que não só melhor concentre em seus livros uma série de tendências transversais e correlatas, implicadas às novas convergências tecnológicas, mas também aquele que levou mais longe a formulação de um novo programa, paradigma e/ou filosofia da imortalização tecnológica, a qual, tomando de empréstimo um termo cunhado por escritor de ficção científica, Vernor Vinge, ele batizou de singularidade.

No livro The singularity is near: when humans transcend biology (A singularidade está próxima: quando os seres humanos transcendem a biologia), publicado em 2005, e ainda sem tradução para o português, Kurzweil sugere estar em curso uma surpreendente elevação da capacidade de conhecimento dos seres humanos, a qual deverá transformar radicalmente a nós mesmos e o mundo com o qual estamos familiarizados. Esse processo tornou-se possível devido ao crescimento exponencial da capacidade de armazenamento e processamento de informações dos computadores; tal aceleração tecnológica, por outro lado, terminará por fazer com que as máquinas inteligentes muito em breve superem as capacidades cognitivas humanas, ensejando uma aguda e abrupta descontinuidade no curso do progresso evolucionário, ruptura esta marcada por uma hiperaceleração da ciência, acontecimento que constitui propriamente o advento da singularidade de que fala
Kurzweil. Enquanto o processo não chega a esse ponto de inflexão, o que se pode fazer é ater-se ao domínio biológico, investindo o corpo orgânico de uma série de cuidados, que envolvem desde dietas cuidadosamente planejadas, até exercícios físicos regulares, passando por suplementações vitamínicas e acompanhamento médico preventivo.

Com tais iniciativas, supõe-se ser possível, provisoriamente, retardar o envelhecimento. O problema, no entanto, é que isso não pode ser feito indefinidamente, pois nossa biologia tem limites que lhe são inerentes, o que cedo ou tarde terminará por impor a tarefa de uma remodelação desse corpo orgânico, de modo a corrigir suas imperfeições, curar seus processos mórbidos e maximizar suas potências. $\mathrm{O}$ autor esclarece em que direção deve seguir esse processo, e ela passa inevitavelmente pela reengenharia de todos os órgãos e sistemas do corpo e do cérebro; além disso, com o recurso à nanotecnologia, nanorobôs deverão operar molecularmente em nossos organismos, revertendo o envelhecimento e melhorando nossas capacidades cerebrais. Daí, logicamente, para a fusão entre a inteligência humana e a artificial, trata-se apenas de um passo, ao cabo do qual nossa porção artificial passará a ser cada vez mais preponderante, enquanto que nós tenderemos a uma desmaterialização, como bem observa Gray (2013, p. 196):

Ao terem deixado de ser organismos biológicos, os seres humanos não possuirão as vulnerabilidades das formas naturais de vida. Eles adquirirão "corpos", mas estes serão entidades virtuais, ou foglets - aglomerações de nanorobôs que podem mudar de forma à vontade - e "esses corpos feitos pela nanoengenharia serão bem mais capazes e duráveis do que os corpos biológicos humanos". Esse híbrido máquina-ser-humano viverá a maior parte de sua vida fora ou além do mundo material.

Sobre esses diversos projetos imortalistas, algumas considerações finais merecem ser feitas. Em primeiro lugar, quanto a Kurzweil, apesar de profundamente ancorado numa racionalidade tecnológica, seu projeto possui claramente uma dimensão escatológica que ressoa significativamente com aquela deificação da humanidade característica dos "construtores de Deus". Seria interessante comparar, a título de exemplo, as seguintes palavras de Kurzweil (citado por Gray, 2013, p. 197) àquelas de Máximo Gorki, que citei minutos atrás:

A lei dos retornos acelerados continuará até que a inteligência não biológica chegue perto de "saturar" a matéria e a energia em nosso setor do universo com nossa inteligência humano-mecânica (...). Em última instância, todo o universo se tornará saturado com nossa inteligência. Esse é o destino do universo. 
A segunda e a terceira observações, muito perspicazes e oportunas, são de responsabilidade de John Gray, a primeira delas dizendo respeito a um paradoxo que o paradigma da singularidade de Kurzweil encerra. O caso é que a imortalidade buscada $n a$ e pela singularidade implica em uma extinção dos indivíduos humanos. Com efeito, se nossas consciências são enviadas ao virtual, ou seja, a uma espécie de nuvem de informação, nuvem esta que abarca e engole todo o cosmos, o que resta efetivamente dos indivíduos humanos? Nas palavras de Gray (2013, p. 200):

O imortalismo é um programa de extinção humana, um ato de desaparecer mais completo do que qualquer outro que pareça provável no curso natural dos eventos. Os seres humanos certamente vão desaparecer; mas a extinção não significa nada além ao caos Imortal de onde vieram. No cenário imortalista, os seres humanos engendram sua própria extinção: ao intervir no processo evolutivo para criar uma nova espécie, o animal que ansiava viver para sempre colocou fim à sua própria existência.

A terceira observação, por sua vez, aplica-se a todos os tipos de imortalismos a que me referi nesta exposição; meio que suspendendo boa parte foi descrito até aqui, indaga sobre qual seria a real motivação do imortalismo e da singularidade. Seria de fato o intuito de derrotar a morte e exorcizar a finitude humana? Gray tem lá suas dúvidas e arrisca-se a dizer que, na verdade, a motivação profunda desses projetos reside mais propriamente, na tentativa de escapar à contingência e ao mistério. $\mathrm{O}$ que inquietaria os entusiastas dos projetos imortalistas, segundo o autor (Gray, 2013, p. 200), seria, de um lado, o acaso, o imprevisível, e, de outro, a desmedida e a desordem que parecem imanentes ao cosmos, à vida, à existência humana:

A busca da imortalidade através da ciência é apenas incidentalmente um projeto que se propõe a derrotar a morte. No fundo, é uma tentativa de escapar à contingência e ao mistério. Contingência significa que os seres humanos serão sempre sujeitos ao destino e ao acaso; mistério significa que sempre estarão rodeados pelo incognoscível. Para muitos, esse estado de coisas é intolerável, mesmo impensável. Ao valer-se do conhecimento que avança, insistem eles, o animal humano pode transcender a condição humana.

Tais palavras parecem afinar-se perfeitamente ao que pensa o físico Gleiser (2014, p. 328) sobre a ciência, quando afirma que esta reflete "a inquietude humana, nossa necessidade de ter algum controle sobre o tempo, sobre o misto de veneração e temor que sentimos quando confrontamos a imensidão do cosmos". Por fim, elas me remetem a Nietzsche e me levam a perguntar se alguém que tem pela vida um amor fati, que não se move pela necessidade de consumir modos de vida estereotipados secretados pelo sistema e não se satisfaz com suas promessas vãs de paraísos artificiais - em suma, levam-me a indagar se tal indivíduo ansiaria pela imortalidade ou necessitaria dela.

\section{Referências}

Arantes, P. (2014). O caos como regra (Entrevista a Patrícia Pereira). Revista Filosofia, 114, 1-2. Disponível em: http://filosofiacienciaevida.uol.com.br/ESFI/ Edicoes/19/artigo72740-1.asp

Cadwalladr, C. (2012, 6 de maio). 'Thinktank' do futuro. Jornal Folha de São Paulo. Recuperado dehttp:// www1.folha.uol.com.br/fsp/ilustrissima/41125-thinktank-do-futuro.shtml

Carneiro, H. (2011, 25 de maio). Drogas: muito além da hipocrisia. Post no Blog Outras Palavras. Recuperado dehttp:/outraspalavras.net/posts/drogas-muito-alemda-hipocrisia/

Deleuze, G. (1992). Post-scriptum sobre as sociedades de controle. In G. Deleuze, Conversações (Coleção Trans, pp. 219 -226). Rio de Janeiro: Ed. 34.

Ettinger, R. C. W. (1964). The prospect of immortality. NY: Doubleday.

Foucault, M. (2008). Nascimento da biopolítica. Curso no Collège de France (1978 - 1979). São Paulo: Ed. Martins Fontes.

Gleiser, M. (2014). A ilha do conhecimento: Os limites da ciência e busca pelo sentido. Rio de Janeiro: Ed. Record.

Gray, J. (2014). A busca pela imortalidade: A obsessão humana e ludibriar a morte. Rio de Janeiro: Editora Record.

Harrington, A. (1969). The imortalist: an approach to the engineering of man's divinity. Random House.

Kurzweil, R. (2005). The singularty is near: when humans transcend biology. Penguin Books.

Lima, H. L. A. (2010). Do corpo-máquina ao corpoinformação: $O$ pós-humanismo como horizonte biotecnológico. Curitiba: Editora Honoris Causa.

Oliveira, M. (2012, 24 de fevereiro). A era dos homens imortais. Revista ISTO É Independente, 2207, 
Seção Medicina \& Bem-Estar. Recuperado dehttp:// www.istoe.com.br/reportagens/paginar/192193 A+ERA+DOS+HOMENS+IMORTAIS/1.

Pelbart, P. P. (2013). O avesso do niilismo: Cartografias do esgotamento. São Paulo: N-1 Edições.

Rifkin, J. (2001). A era do acesso: A transição de mercados convencionais para networks e o nascimento de uma nova economia. São Paulo: Pearson Education do Brasil; Makron Books.

Rose, N. (2013). A Política da própria Vida: Biomedicina, poder e subjetividade no século XXI. São Paulo: Editora Paulus, Coleção Biopolíticas.

\section{Endereço para correspondência:}

Sylvio Gadelha

Endereço: Rua Bento Albuquerque, n ${ }^{\circ}$ 550, apto. 102,

Cocó. Fortaleza/CE. CEP 60192-060.

E-mail: thalita_1@yahoo.com.br 